\title{
Surgical Bypass versus Endoscopic Stenting for Unresectable Head Pancreatic Cancer, Which Palliative Treatment Is Better in Developing Countries, Morocco as an Example
}

\author{
Khalid Mazine, Hamdaoui Mohammed, El Ghazi Karima, Ousadden Abdelmalek, Mazaz Khalid, \\ Ibrahimi Adil, Ait Taleb Khalid, Benajeh Dafrallah, Benjelloun Elbachir
}

Department of Visceral Surgery, Faculty of Medicine and Pharmacy of Fez, University Hospital Hassan II-Fes, Sidi Mohamed Ben Abdellah University, Fez, Morocco

Email: khalid.mazine@gmail.com

How to cite this paper: Mazine, K., Mohammed, H., Karima, El.G., Abdelmalek, O., Khalid, M., Adil, I., Khalid A.T., Dafrallah, B. and Elbachir, B. (2017) Surgical Bypass Versus Endoscopic Stenting for Unresectable Head Pancreatic Cancer, Which Palliative Treatment Is Better in Developing Countries, Morocco as an Example. Open Journal of Gastroenterology, 7, 154164.

https://doi.org/10.4236/ojgas.2017.75017

Received: March 17, 2017

Accepted: May 23, 2017

Published: May 26, 2017

Copyright $\odot 2017$ by authors and Scientific Research Publishing Inc. This work is licensed under the Creative Commons Attribution International License (CC BY 4.0).

http://creativecommons.org/licenses/by/4.0/

\section{(c) (†) Open Access}

\begin{abstract}
Background: Metal stents for unresectable pancreatic cancer are associated with longer patency and superior cost-effectiveness. However, they are too expensive to be recommended routinely in developing countries. Moreover, a debate on outcome results in these patients who receive plastic biliary endoprothesis versus surgical bypass as palliation of obstructive jaundice. We aimed to compare retrospectively the outcomes in patients treated with plastic stent or surgical bypass as a palliative option for these patients. Patients and Methods. We have examined data for patients $(\mathrm{n}=86)$ who received endoscopic stenting $(\mathrm{n}=64)$ or surgical bypass $(\mathrm{n}=22)$, from January 2013 to November 2016, as a palliative treatment for obstructive jaundice from inoperable cancer head pancreas. Results. Serum bilirubin and CA19.9 levels were comparable in age and gender matched patient groups. Moreover, post-operative major complications and 30-days mortality showed no significant differences among patient groups. However, surgical bypass treated patients showed longer initial hospital stay ( 9 vs. 6 days, $\mathrm{p}=0.014$ ), higher cost ( $\$ 1600$ vs. $\$ 1088$ ) and longer survival (192 vs. 101 days, $p=0.003$ ) compared to endoscopy-stenting treated patients. Re-hospitalization was required for 5 stented patients (averaged \$448). Conclusion: Biliary bypass surgery for unresectable pancreatic cancer may improve patient survival, although prolongs hospital stay. It may be recommended for relatively fit patients with a life expectancy of 6 months and more.
\end{abstract}

\section{Keywords}

Pancreatic Carcinoma, Jaundice, Palliative Treatment, Biliary Bypass, Endoscopy Stent 


\section{Introduction}

Pancreatic cancer is one of the leading causes of cancer related mortality all over the world. About $80 \%$ of pancreatic carcinomas are located in pancreas head, and adenocarcinomas comprise $75 \%$ of them [1]. Strong evidence from previous studies showed that complete resection is the only chance for cure, which is possible only in $10 \%-20 \%$ of patients [2]. Thus, palliative managements are the sole treatment options for about $80 \%$ of pancreatic cancer patients. Obstructive jaundice is the most common presenting symptom, which is associated with pruritus, recurrent attacks of cholangitis, and liver dysfunction that dramatically affect the life quality of patients. Resolving biliary obstruction is very critical for those patients, which can be through surgical bypass or placement of a biliary stents by cutaneous or endoscopic approach [3].

Stenting is desirable to surgical bypass by its minimal invasion and short hospitalization time [4]. However, operative bypass has a $2 \%-5 \%$ rate of recurrent jaundice, and provides an opportunity for gastrojejunostomy in cases with duodenal obstruction [5]. Debates, on choosing surgical bypass or biliary stenting procedure, have been reported by several prospective and retrospective studies which have shown superiority of one treatment comparing to the other [3] [6] [7], Furthermore, there are only few researchers who have examined the cost effectiveness of each of these two procedures [8] [9].

This study aimed to evaluate our experience in Morocco on treating patients, by surgical biliary bypass or endoscopic stenting, presented by obstructive jaundice from advanced cancer head pancreas and to compare the patient's outcome in terms of post procedure mortality, morbidity, assess cost effectiveness, re-hospitalization and overall survival in these patients.

\section{Materials and Methods}

Study Design and Patients Selection: This study was performed according to the declaration of Helsinki and approved by the Local Ethical Committee. All patients presented with obstructive jaundice due to pancreatic head carcinoma and treated in University Hospital Hassan II, Fez, Morocco, from January 2013 to November 2016 were enrolled in this study. Cancer diagnosis was based on medical history, clinical examination, endoscopy and imaging findings, bilirubin/CA 19.9 levels and histopathology confirmation. Decision to perform endoscopic stenting or surgery was taken based on our interdisciplinary discussion on the best options for patient health status considering cancer staging.

Over 4 year period, 135 patients were reviewed to be enrolled in this study (Figure 1). Exclusion criteria were any patient who: 1) needs curative surgery (pancreatico-duoden-ectomy), in whom decision of therapeutic abstention was taken, 2) failed or received endoscopic treatment other than biliary endoprothesis, 3) requires imaging-guided percutaneous trans-hepatic biliary drainage and 4) is a candidate for surgical treatment other than biliary bypass. Follow-up was obtained from the clinical records and through telephone interviews. The following parameters were examined for all patients groups; procedure success, 


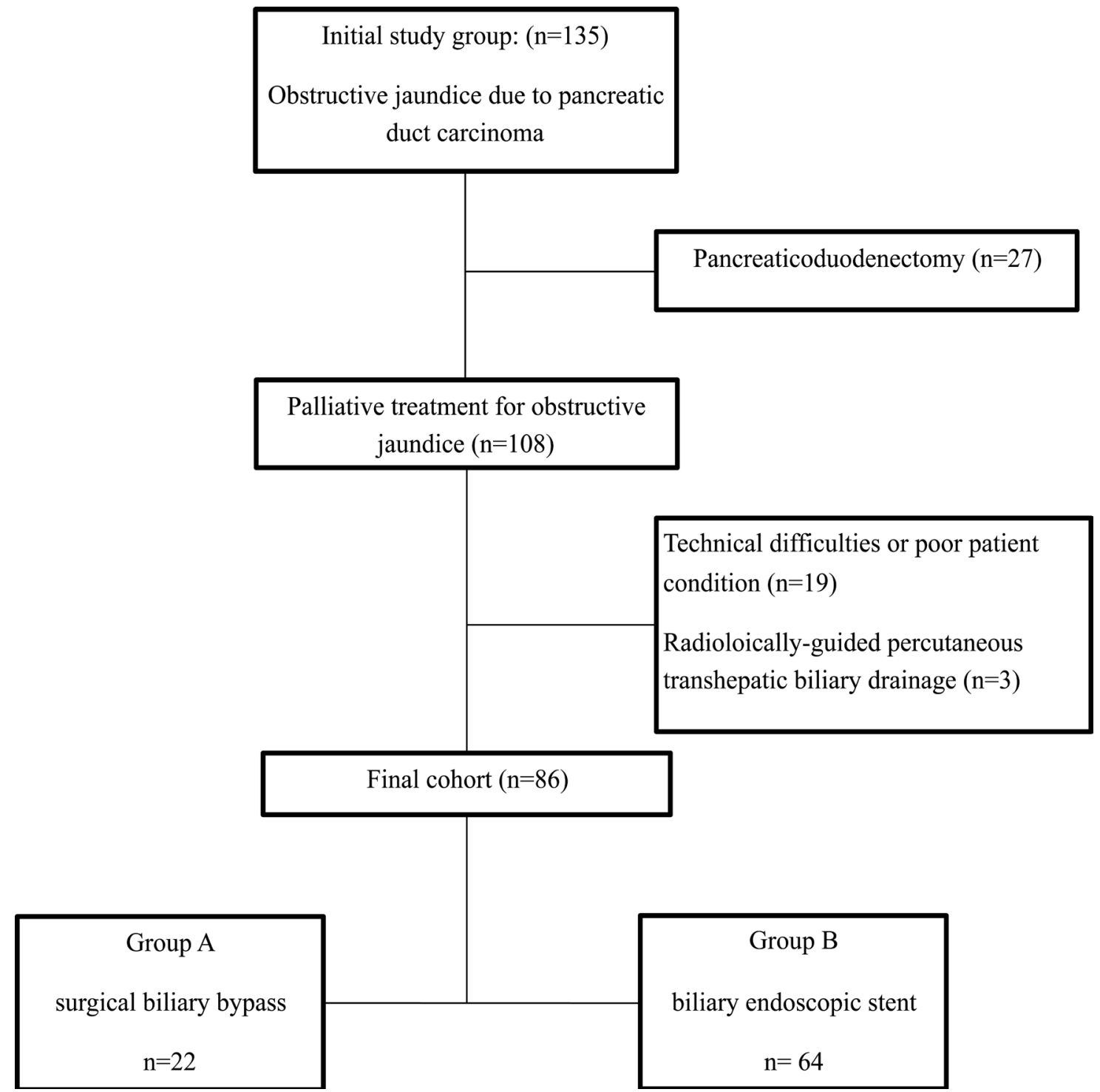

Figure 1. Study design flowchart. Final cohort study was chosen from originally 135 inoperable cancer head pancreas. Palliative treatment was required for 108 patients, out of them 86 patients were included in our study.

post procedure complications, 30-days mortality, hospital stay duration following the treatment, jaundice recurrence rate and subsequent re-hospitalization, overall survival and cost effectiveness of each procedure.

\section{Surgical Bypass Procedure}

Palliative biliary drainage surgery was done for all inoperable cancer head pancreas. A bypass comprises hepatico-duodenostomy or an end-to-side Rouen-Y hepatico-jejunostomy after gallbladder removal. Gastro-jejunostomy was performed in patients who had a high risk for duodenal obstruction during the survival period, such as in cases with duodenal invasion. No patient underwent prophylactic gastro-jejunostomy. Patients received palliative chemotherapy as well on an individual basis.

\section{Endoscopic Stenting Procedure}

A therapeutic stenting procedure, through a side-viewing fluoroscopic guided 
endoscopy, was done for patients to drain biliary tract using a plastic endoprosthesis. The stent position was confirmed by its anatomic location, visualization of bile drainage through injection a contrast dye into the stent following placement to ensure its position above bile duct stricture.

\section{Statistical Analysis}

Overall survival, in this study, was calculated from the day of treatment start to patient death or loss of follow up. Chi square test, Fisher's exact test, or unpaired t-tests were used, according to their distribution, to examine patients' data in both groups. Results were expressed as means \pm SD. Kaplan-Meier method was used to examine the cumulative survival in both patient groups. A $p$ value $<$ 0.05 was considered statistically significant.

\section{Results}

From 135 patients admitted for obstructive jaundice due to pancreatic duct carcinoma, 49 patients were excluded from the study as per Figure 1. Curative Whipple's operation surgery (pancreatico-duodenectomy) was possible in $27 \mathrm{pa}-$ tients. Endoscopic stent implantation and/or surgery were impossible due to technical difficulties or poor patient condition in 19 patients. Percutaneous trans-hepatic cholangio-drainage (PTCD) was done for 3 patients. Local vascular invasion of the inoperable pancreatic cancer occurred in 44 patients to superior mesenteric vein (SMV), portal vein, superior mesenteric artery (SMA), hepatic artery or celiac artery. Distant metastasis was confirmed in 42 patients. Eighty patients were finally classified into 2 groups in this study; surgery group (surgical biliary bypass, $\mathrm{n}=22$ ), endoscopy group (biliary endoscopic stent placement, $\mathrm{n}=64$ ) (Figure 1).

\section{Patient's characteristics}

Both patients groups were matched for age/gender and comorbidities, bilirubin and CA 19.9 level and presence of liver metastasis (Table 1). Percentages of patients, who were diagnosed in stage III/IV or received adjuvant chemotherapy, were comparable in patients groups ( $p>0.05$ for both). In surgery group, $14 \mathrm{pa}-$ tients were stage III while 8 patients were stage IV. In endoscopy group, 30 patients were stage III and 34 were stage IV. In the surgery group 16 patients underwent choledocho-duodenostomy and 5 patients a roux-en-Y hepatico-je- junostomy for biliary bypass procedure. Only one patient required double bypass (hepatico-jejunostomy + gastro-jejunostomy) due to tumor infiltration of the duodenum.

\section{Morbidity and 30-day mortality (Table 2)}

Comparable 30-day mortality was observed in both patient groups $(p=0.25)$. Overall complications, defined as those events occurring within 30 days following procedure, was significantly higher in surgery group (36.4\%), compared to endoscopy group $(10.9 \%)(p=0.006)$. Minor complications such as biliary fistula occurred in $27.3 \%$ of surgery patient group, while mild pancreatitis occurred in $3.1 \%$ of endoscopy stented patients $(p=0.0001)$. Major complications were comparable in patients groups $(p=0.54)$. In surgery group; 2 patients have de- 
Table 1. Demographic and clinical characteristics of patients groups.

\begin{tabular}{cccc}
\hline & $\begin{array}{c}\text { Surgery group } \\
(\mathbf{n}=\mathbf{2 2})\end{array}$ & $\begin{array}{c}\text { Endoscopy group } \\
(\mathbf{n}=64)\end{array}$ & $P$ value \\
\hline Gender (n, \%): & & & \\
Male & 15,68 & 37,58 & 0.39 \\
Female & 7,32 & 27,42 & 0.72 \\
Age (median,year) & $61.3 \pm 9.6$ & $62.4 \pm 13.3$ & 0.45 \\
Diabetes (\%) & 22.7 & 18.8 & 0.94 \\
Blood Urea (g/L) & $0.3 \pm 0.1$ & $0.4 \pm 0.3$ & 0.36 \\
Bilirubin (median, kU/L) & $217.4 \pm 79.9$ & $238 \pm 96$ & 0.61 \\
CA19.9 (median, kU/L) & $792 \pm 613$ & $1273 \pm 2707$ & 0.08 \\
Livermetastasis (n, \%) & $4(18)$ & $28(44)$ & 0.53 \\
Peritoneal Dissemination (n, \%) & $1(4.54 \%)$ & $4(6.25)$ & 0.11 \\
Stage III/IV (n) & $14 / 8$ & $30 / 34$ & 0.37 \\
\hline Adjuvant Chemotherapy (n) & 6 & 9 &
\end{tabular}

Table 2. Mortality within 30 days as well as major or minor complications in patients groups.

\begin{tabular}{cccc}
\hline & $\begin{array}{c}\text { Surgery group } \\
(\mathbf{n}=22)\end{array}$ & $\begin{array}{c}\text { Endoscopy group } \\
(\mathbf{n}=64)\end{array}$ & $p$ \\
\hline Mortality, 30-day (n, \%) & $2(9)$ & $2(3)$ & 0.25 \\
OverallComplications (n, \%) & $8(36.4)$ & $7(10.9)$ & 0.006 \\
Major (n, \%): & $2(9.1)$ & $5(7.8)$ & 0.54 \\
Minor (n, \%): & $6(27.3)$ & $2(3.1)$ & $\mathbf{0 . 0 0 0 1}$ \\
\hline
\end{tabular}

veloped biliary peritonitis. In endoscopy stented group; 2 patients had severe cholangitis, 1 patient had severe pancreatitis, and 1 patient had gastrointestinal hemorrhage.

\section{Procedure Success}

Success was considered if at least $50 \%$ fall in preoperative serum bilirubin level within 2 weeks associated with patient's symptoms improvement. It was achieved in 54 (84.3\%, Table 2 and Table 3) of 64 stented patients with 10 failure cases; 6 stented failed patients were underwent successful surgical bypass, one patient was treated by PTCD and one patient was not eligible for any other palliative treatment. Two patients died from severe cholangitis in endoscopy group within 30 days. In the surgery group success was achieved in 17 (86.3\%) patients. Two patients died from postoperative biliary peritonitis (Table 2 and Table 3).

\section{Re-admission and Hospital Stay (Table 3)}

Re-admission to hospital was needed on 7 occasions in stented patients for jaundice recurrence due to stent obstruction $(n=2)$ or migrations $(n=5)$. Endoprosthesis replacement was performed successfully in 6 patients, while 1 pa- 
Table 3. Percentage of success, survival, hospital stay and average cost in US dollar in patient groups who received surgical bypass or plastic stent insertion.

\begin{tabular}{cccc}
\hline & $\begin{array}{c}\text { Surgery group } \\
(\mathrm{n}=\mathbf{2 2})\end{array}$ & $\begin{array}{c}\text { Endoscopy group } \\
(\mathrm{n}=64)\end{array}$ & $P$ value \\
\hline Procedural Success (\%) & 86.3 & 84.3 & $>0.05$ \\
Re-Admission (\%) & 0 & 10.9 & 0.1 \\
Survival (days) & 192 & 101 & 0.003 \\
Mean Hospital Stay (days) & 9 & 6 & 0.014 \\
Cost (US dollars) & $\$ 1600$ & $\$ 1088$ & --- \\
\hline
\end{tabular}

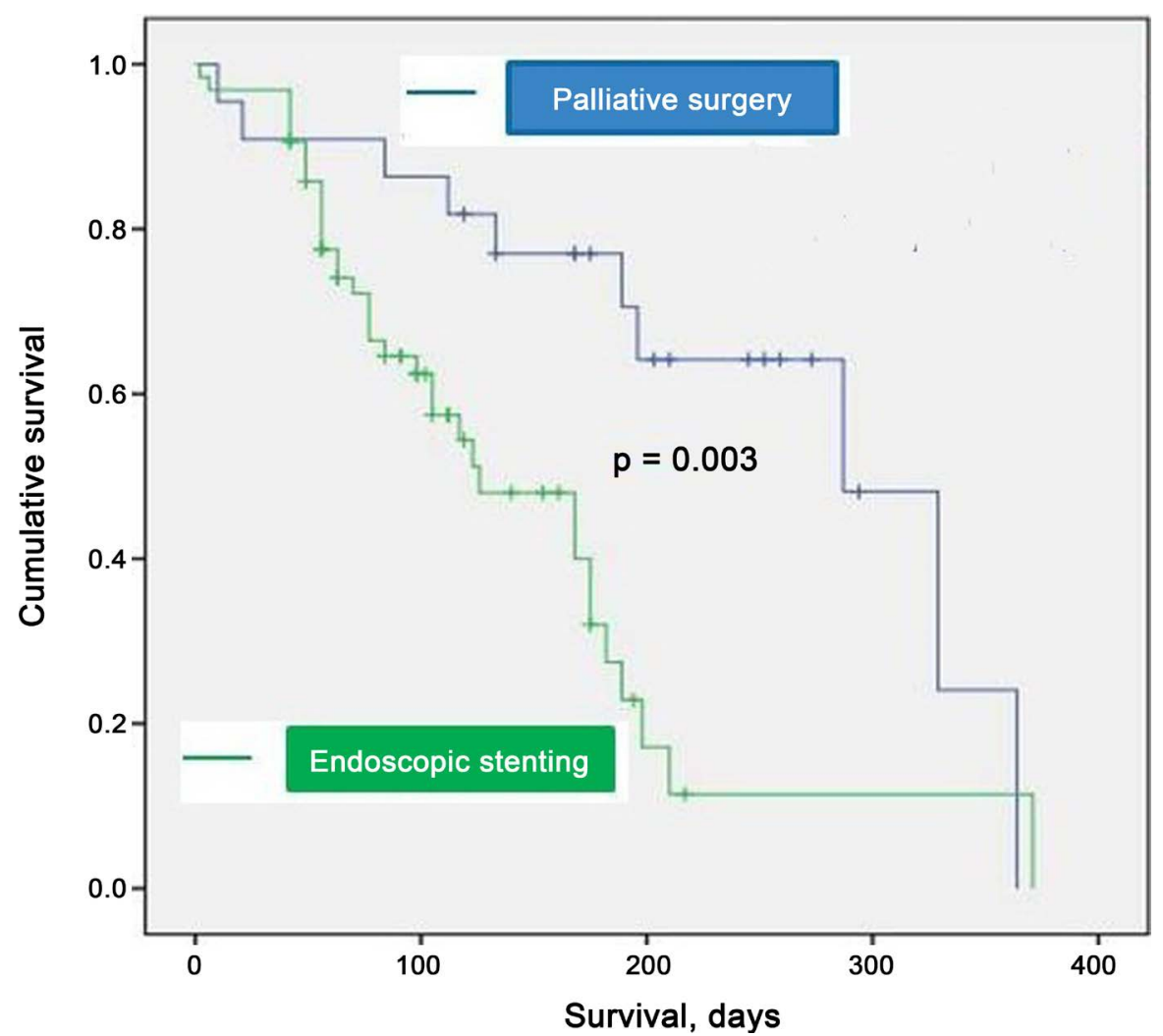

Figure 2. Kaplan Survival curve for patients treated with surgical bypass vs. endoscopy plastic stenting for palliative management of obstructive jaundice resulting from inoperable cancer head pancreas.

tient got surgical biliary bypass. No jaundice recurrence or others causes as duodenal obstruction necessitating readmission was required in surgery group. Despite more re-admissions, total hospital stay for those patients treated endoscopically was significantly lower than those in surgery group ( 9 vs. 6 days, $p=$ 0.014, Table 3).

\section{Patient's Survival (Table 3)}

Kaplan Meier curve showed of patients undergoing palliative bypass was significantly higher than in stented patients compared to surgery patient group (192 vs. 101 days, $p=0.003$ ) (Figure 2).

\section{Total Hospitalization Cost}

Total hospitalization cost, including re-hospitalization after initial treatment, 


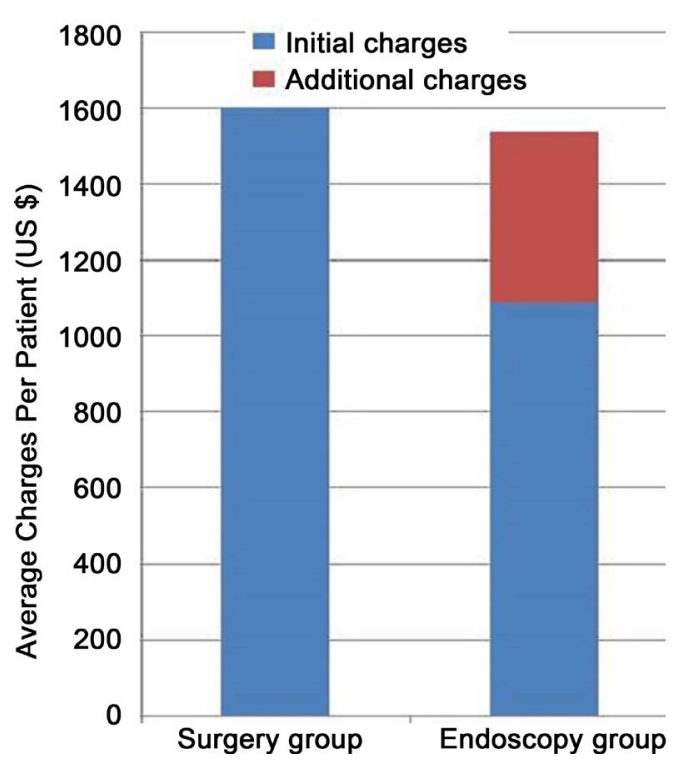

Figure 3. Total hospitalization cost.

was calculated as per hospital charges collected from patient insurance agent according to hospital management information. It covered cost for: hospital stay, for procedure which includes operating room time and consumables used during patient surgeries as well as the plastic stents costs and medications. Average initial hospital stay for surgically treated patients was 9 days, with mean total charges of $\$ 1600$ per patient in surgery group (Figure 3). No re-hospitalization in this group. Patient initial charges were significantly higher for surgery patients compared to endoscopy stented patients ( $\$ 1600$ vs. $\$ 1088$ per patient). However, additional charges were added for re-hospitalization of patients in endoscopy stented patients group. Although it remained lower than compared to surgical group (\$1600 vs. $\$ 1488$ per patient, Figure 3).

\section{Discussion}

Long-term outcome of pancreatic cancer is extremely poor, the overall median survival from diagnosis being 3- 6 months without treatment, which increases to around 23 months with curative surgery and adjuvant treatment [10]. Thus overall the majority of patients will have palliative treatment and therefore palliation of symptoms will still be an important focus. The three most important symptoms that should be treated in advanced pancreatic cancer are pain, duodenal obstruction and mainly obstructive jaundice which is present at the time of diagnosis in up to $90 \%$ of patients [11] [12]. The first biliary endoprosthesis was performed in 1979 [13]. It has been in our practice few years ago only, mainly due to the absence of technical platform. In our practice it has become an alternate method for the palliative therapy of malignant biliary tract obstruction. The most common form of morbidity associated with endoprosthetic drainage remains stent occlusion, which may result in recurrent jaundice and cholangitis. Stent occlusion requiring replacement occurs in $6 \%-23 \%$ (11\% in our study) of patients with conventional plastic stents [14] [15] [16]. Expandable metallic bi- 
liary endoprostheses were expected to incur a longer patency, however their high price makes them inabordable for our patients. Determining the comparable efficiency of endoscopic stenting and surgical biliary bypass requires evaluation of multiple factors. Major complications of $7.81 \%$ and $9.09 \%$ for the stented and surgical patients, respectively, were not statistically different. However, surgical patients were hospitalized for a significantly longer period of time than stented patients (9 vs. 6 days) after the initial therapeutic procedure. Patients undergoing endoscopic stenting incurred an increased rehospitalization rate primarily related to stent changes. These results of the effectiveness of endoscopic versus surgical bypass for palliation of biliary obstruction are comparable with the previously published prospective studies (Table 4) [6] [16] [17] [18] [19]. In a randomized trial, Schwarz et al. [20] concluded that endoprosthesis should be placed if there was evidence of metastatic disease or if the patient is not eligible for surgery. However, meta-analysis conducted by Taylor et al. [14] concluded that more treatment sessions were required after stent placement than after surgery, mainly due to jaundice recurrence after stent obstruction or migration, which means more re-hospitalization and higher cost. Our study did not support this finding as the medical group patients accrued slightly lower average charges in all categories. The randomized study performed by Smith et al. [4] showed that the median survival of patients who underwent surgical bypass is longer than that of patients who were treated with endoscopic stent placement. Our study along with other retrospective studies showed similar results (Table 4). Contrariwise to prospective studies performed by Bornmann et al. [15], Shepherd

Table 4. Previous studies as well as current study patients' data comparison regarding success, morbidity, 30-days mortality, jaundice recurrence and patient survival.

\begin{tabular}{|c|c|c|c|c|c|c|c|c|c|}
\hline Study & Type & Treatment & $\begin{array}{l}\text { Patients } \\
\text { (n) }\end{array}$ & $\begin{array}{c}\text { Success } \\
(\%)\end{array}$ & $\begin{array}{l}\text { Morbidity } \\
\text { (n) }\end{array}$ & $\begin{array}{c}30 \text { day-mortality } \\
\text { (n) }\end{array}$ & $\begin{array}{c}\text { Mean } \\
\text { Hospital } \\
\text { stay (days) }\end{array}$ & $\begin{array}{c}\text { Recurrent } \\
\text { jaundice } \\
(\%)\end{array}$ & $\begin{array}{r}\text { Survival } \\
\text { (weeks) }\end{array}$ \\
\hline \multirow{2}{*}{ Bornman et al. 1986 (22) } & \multirow{2}{*}{ Randomized } & Endoscopy & 25 & 84 & 28 & 8 & 18 & 38 & 19 \\
\hline & & Surgery & 25 & 76 & 32 & 20 & 24 & 16 & 15 \\
\hline \multirow{2}{*}{ Shepherd et al. 1988 (23) } & \multirow{2}{*}{ Randomized } & Endoscopy & 23 & 82 & 30 & 9 & 5 & 30 & 22 \\
\hline & & Surgery & 25 & 92 & 56 & 20 & 13 & 0 & 18 \\
\hline \multirow[t]{2}{*}{ Andersen et al. 1989 (24) } & \multirow{2}{*}{ Randomized } & Endoscopy & 25 & 96 & 36 & 20 & 26 & 0 & 12 \\
\hline & & Surgery & 25 & 88 & 20 & 24 & 27 & 0 & 14 \\
\hline \multirow[b]{2}{*}{ Smith et al. 1994 (3) } & \multirow[b]{2}{*}{ Randomized } & Endoscopy & 101 & 92 & 30 & 8 & 19 & 36 & 22 \\
\hline & & Surgery & 100 & 92 & 58 & 15 & 26 & 2 & 16 \\
\hline \multirow{2}{*}{ Scott et al. 2008 (8) } & \multirow{2}{*}{ Retrospective } & Endoscopy & 33 & NA & $\mathrm{NA}$ & 18.1 & 34.1 & NA & 19.2 \\
\hline & & Surgery & 23 & NA & NA & 4.3 & 10.2 & NA & 54.5 \\
\hline \multirow{2}{*}{ Distler M et al. 2010 (7) } & \multirow{2}{*}{ Retrospective } & Endoscopy & 138 & NA & 5.1 & 2.2 & NA & NA & 22 \\
\hline & & Surgery & 41 & NA & 14.6 & 2.4 & NA & 4 & 27 \\
\hline \multirow{2}{*}{ Current } & \multirow{2}{*}{ Retrospective } & Endoscopy & 64 & 86.5 & 10.9 & 3.1 & 6 & 10.9 & 14.4 \\
\hline & & Surgery & 22 & 84.6 & 36.3 & 9 & 9 & 0 & 27.4 \\
\hline
\end{tabular}


et al. [21], and Smith et al. [4], which showed that patients who had undergone endoscopic stent placement seemed to have a survival benefit compared to surgical patients (Table 4). This controversy in the results may be explained by the selected patients in surgery group, as most of these patients were thought to have a resectable tumor after conventional radiological staging. It may be also explained by the great number of metastatic disease in the endoscopic group, however exclusion of patients with metastasis in both groups give similar results. Worthy of note that median survival in our patients in both groups is relatively bad when compared to recent studies. The reason is that of only a small number of patients could benefit from adjuvant treatment, either because of patients/family choice or lack of resources. Furthermore only $41.8 \%$ of cancers were diagnosed based on histologic analysis with most diagnoses based on clinical and radiologic finding. Those patients could also not benefit from chemotherapy. This is the first published study to compare costs between patients undergoing endoscopic or surgical bypass in developing countries. The absolute monetary value may vary depending on the institution's geographic location. The cost of hospital stay and procedure significantly vary between countries with high and those with Low to Middle income. For instance in the study of Raikar et al. [8] from Mayo clinic USA, the initial hospital stay was $\$ 18,325$ for surgical patients (mean 14 days), compared to $\$ 1600$ in our institution (mean 9 days). In endoscopic group the hospital stay charges were $\$ 9663$ (mean 7 days) compared to $\$ 1088$ (mean 6 days) in our hospital. Twelve stented patients required re-hospitalization (average charge of \$4029) compared to seven patients required re-hospitalization (average charge of $\$ 400$ ). These data demonstrate that beyond the availability of surgeons, endoscopists and adequate technical platform, there are additional barriers to providing basic cancer surgical services in low to middle income countries. Patients require an accurate cancer diagnosis and appropriate cancer staging to optimize surgical or endoscopic decision making. More resources are needed for the best palliative care including adjuvant treatments. The present study was relatively small, and the treatment selection was biased by several factors: accuracy of preoperative staging, surgeon's preference for method of treatment. However, the strengths and weakness of the two treatment policies could be evaluated in our context. Endoscopic stenting should be reserved for patients with a poor prognosis and/or general inoperability.

\section{References}

[1] Luttges, J. and Kloppel, G. (2005) Pancreatic Ductal Adenocarcinoma and Its Precursors. Der Pathologe, 26, 12-17.

[2] Tempero, M.A., Arnoletti, J.P., Behrman, S.W., Ben-Josef, E., Benson, A.B., Casper, E.S., Cohen, S.J., Czito, B., Ellenhorn, J.D., Hawkins, W.G., et al. (2012) Pancreatic Adenocarcinoma, Version 2.2012: Featured Updates to the NCCN Guidelines. Journal of the National Comprehensive Cancer Network, 10, 703-713. https://doi.org/10.6004/jnccn.2012.0073

[3] Distler, M., Kersting, S., Ruckert, F., Dobrowolski, F., Miehlke, S., Grutzmann, R. 
and Saeger, H.D. (2010) Palliative Treatment of Obstructive Jaundice in Patients with Carcinoma of the Pancreatic Head or Distal Biliary Tree. Endoscopic Stent Placement vs. Hepaticojejunostomy. Journal of the Pancreas, 11, 568-574.

[4] Smith, A.C., Dowsett, J.F., Russell, R.C., Hatfield, A.R. and Cotton, P.B. (1994) Randomised Trial of Endoscopic Stenting versus Surgical Bypass in Malignant Low Bileduct Obstruction. The Lancet, 344, 1655-1660.

[5] Maosheng, D., Ohtsuka, T., Ohuchida, J., Inoue, K., Yokohata, K., Yamaguchi, K., Chijiiwa, K. and Tanaka, M. (2001) Surgical Bypass versus Metallic Stent for Unresectable Pancreatic Cancer. Journal of Hepato-Biliary-Pancreatic Surgery, 8, 367373. https://doi.org/10.1007/s005340170010

[6] Santagati, A., Ceci, V., Donatelli, G., Pasqualini, M.J., Silvestri, F., Pitasi, F., Sportelli, G. and Fiocca, F. (2003) Palliative Treatment for Malignant Jaundice: Endoscopic vs. Surgical Approach. European Review for Medical and Pharmacological Sciences, 7, 175-180.

[7] Scott, E.N., Garcea, G., Doucas, H., Steward, W.P., Dennison, A.R. and Berry, D.P. (2009) Surgical Bypass vs. Endoscopic Stenting for Pancreatic Ductal Adenocarcinoma. HPB: The Official Journal of the International Hepato Pancreato Biliary Association, 11, 118-124. https://doi.org/10.1111/j.1477-2574.2008.00015.x

[8] Raikar, G.V., Melin, M.M., Ress, A., Lettieri, S.Z., Poterucha, J.J., Nagorney, D.M. and Donohue, J.H. (1996) Cost-Effective Analysis of Surgical Palliation versus Endoscopic Stenting in the Management of Unresectable Pancreatic Cancer. Annals of Surgical Oncology, 3, 470-475. https://doi.org/10.1007/BF02305765

[9] Yeoh, K.G., Zimmerman, M.J., Cunningham, J.T. and Cotton, P.B. (1999) Comparative Costs of Metal versus Plastic Biliary Stent Strategies for Malignant Obstructive Jaundice by Decision Analysis. Gastrointestinal Endoscopy, 49, 466-471.

[10] Warshaw, A.L. and Fernandez-del Castillo, C. (1992) Pancreatic Carcinoma. The New England Journal of Medicine, 326, 455-465. https://doi.org/10.1056/NEJM199202133260706

[11] Morgan, R.G. and Wormsley, K.G. (1977) Progress Report. Cancer of the Pancreas. Gut, 18, 580-596. https://doi.org/10.1136/gut.18.7.580

[12] Singh, S.M., Longmire, W.P. and Reber, H.A. (1990) Surgical Palliation for Pancreatic Cancer. The UCLA Experience. Annals of Surgery, 212, 132-139. https://doi.org/10.1097/00000658-199008000-00003

[13] Burcharth, F., Jensen, L.I. and Olesen, K. (1979) Endoprosthesis for Internal Drainage of the Biliary Tract. Technique and Results in 48 Cases. Gastroenterology, 77, 133-137.

[14] Taylor, M.C., McLeod, R.S. and Langer, B. (2000) Biliary Stenting versus Bypass Surgery for the Palliation of Malignant Distal Bile Duct Obstruction: A Meta-Analysis. Liver Transplantation: Official Publication of the American Association for the Study of Liver Diseases and the International Liver Transplantation Society, 6, 302-308. https://doi.org/10.1053/lv.2000.5196

[15] Bornman, P.C., Harries-Jones, E.P., Tobias, R., Van Stiegmann, G. and Terblanche, J. (1986) Prospective Controlled Trial of Transhepatic Biliary Endoprosthesis versus Bypass Surgery for Incurable Carcinoma of Head of Pancreas. The Lancet, 1, 69-71.

[16] Costamagna, G. and Mutignani, M. (2004) Pancreatic Stenting for Malignant Ductal Obstruction. Digestive and Liver Disease: Official Journal of the Italian Society of Gastroenterology and the Italian Association for the Study of the Liver, 36, 635-638.

[17] Gouma, D.J., van Geenen, R., van Gulik, T., de Wit, L.T. and Obertop, H. (1999) Surgical Palliative Treatment in Bilio-Pancreatic Malignancy. Annals of Oncology: Official Journal of the European Society for Medical Oncologyl ESMO, 4, 269-272. 
[18] Lillemoe, K.D., Sauter, P.K., Pitt, H.A., Yeo, C.J. and Cameron, J.L. (1993) Current status of Surgical Palliation of Periampullary Carcinoma. Surgery, Gynecology \& Obstetrics, 176, 1-10.

[19] Nuzzo, G., Clemente, G., Cadeddu, F. and Giovannini, I. (2004) Palliation of Unresectable Periampullary Neoplasms. "Surgical" versus "Non-Surgical" Approach. Hepato-Gastroenterology, 51, 1282-1285.

[20] Schwarz, A. and Beger, H.G. (2000) Biliary and Gastric Bypass or Stenting in Nonresectable Periampullary Cancer: Analysis on the Basis of Controlled Trials. International Journal of Pancreatology: Official Journal of the International Association of Pancreatology, 27, 51-58.

[21] Shepherd, H.A., Royle, G., Ross, A.P., Diba, A., Arthur, M. and Colin-Jones, D. (1988) Endoscopic Biliary Endoprosthesis in the Palliation of Malignant Obstruction of the Distal Common Bile Duct: A Randomized Trial. The British Journal of Surgery, 75, 1166-1168. https://doi.org/10.1002/bjs.1800751207

\section{Submit or recommend next manuscript to SCIRP and we will provide best} service for you:

Accepting pre-submission inquiries through Email, Facebook, LinkedIn, Twitter, etc. A wide selection of journals (inclusive of 9 subjects, more than 200 journals)

Providing 24-hour high-quality service

User-friendly online submission system

Fair and swift peer-review system

Efficient typesetting and proofreading procedure

Display of the result of downloads and visits, as well as the number of cited articles

Maximum dissemination of your research work

Submit your manuscript at: http://papersubmission.scirp.org/

Or contact ojgas@scirp.org 